\title{
SELECTION IN NATURAL POPULATIONS
}

\author{
H. N. BARBER * \\ University of New South Wales, Australia
}

Received 24.iii.65

\section{INTRODUCTION}

THE literature on selective processes in natural and artificial populations is now so enormous that any attempt to summarise it on a world or even on a continental scale would lead to a boring and lifeless catalogue. Consequently, I will deal mainly with Australian plants and animals. In fact, $I$ believe we in Australia are in a better position to see selection in action because the vegetation there has not suffered the same two catastrophes as those of the north. I refer, first to the catastrophe of 10-20,000 years ago when the tundra came down and randomised genes and populations; second, to that of human exploitation which has transformed western Europe into a beautiful garden and created or extended the deserts in North Africa and the Middle East. Australian deserts and forests and many of the pastures, although battered or changed by 150 years of white exploitation, are in general not man-made nor man-controlled. Selection has sorted out species and genes within their populations in a most spectacular manner and three protagonists of evolution, Darwin, Hooker and Huxley, all had their views coloured by a brief study of these populations.

\section{SELECTION BETWEEN SPECIES}

Let us first start by looking at an example of interspecific selection which will serve to illustrate the magnitude of the changes in selective coefficients between related species.

Bronte in the west of central Tasmania has a rainfall of 40 to 60 inches and low forested hillocks of dolerite project from peaty, button-grass (Mesomelena) plains at an altitude of almost $3000 \mathrm{ft}$. A transect across a hillock would show four eucalypt species-aggregata, dalrympleana, gigantea and pauciflora. The transition (or ecotone) between pauciflora and gigantea is complete in about roo ft., which is near the height of the gigantea trees (fig. I). Eucalypt seeds are small and in the related species regnans, Gilbert (1958) estimates that their terminal velocity is $\mathrm{I}_{1} \cdot 4 \mathrm{ft}$./ $/ \mathrm{sec}$., which leads to the seed-distribution shown in fig. 2. The mean distance travelled by the seeds from these trees, which are over $25^{\circ} \mathrm{ft}$. high, is $117 \mathrm{ft}$. Superposing this figure on the Bronte ecotone shows immediately that the interspecific cline must be the result of very high selective coefficients. We can assume that the mean free path of a seed is about $5^{\circ}$ per cent. of tree

* This is an extended version of a paper of the same title delivered at the opening of the symposium on "Evolution and Selection within Populations", Xth International Botanical Congress, Edinburgh, August 1964 . 
height, i.e. about $50 \mathrm{ft}$. in the Bronte ecotone. The selective agent is not known. But the height above the button-grass plain at which

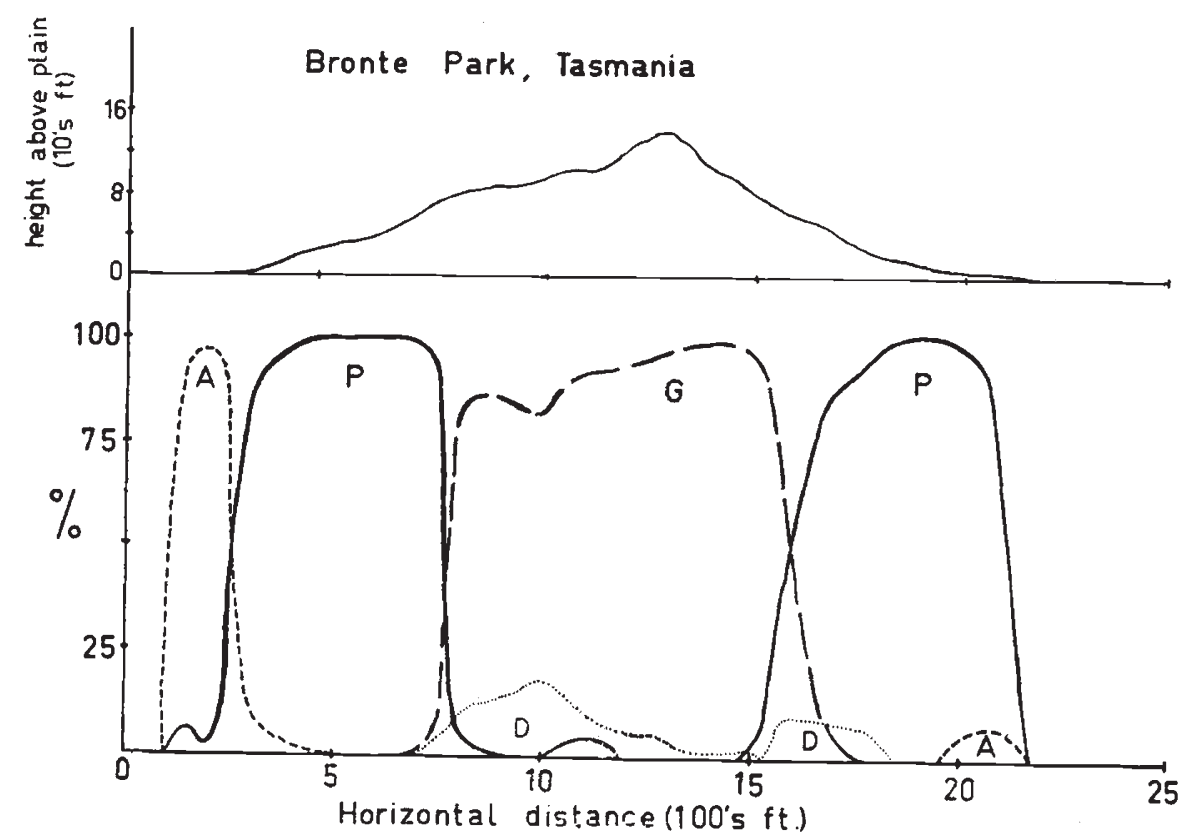

Frc. 1.- Transect through dolerite hillock projecting $150 \mathrm{ft}$. above peaty button-grass plain; Bronte, Tasmania. Upper graph gives section of hillock and lower graphs per cent. frequency of four eucalypt species; A-aggregata, D-dalrympleana, Ggigantea, P-pauciflora.

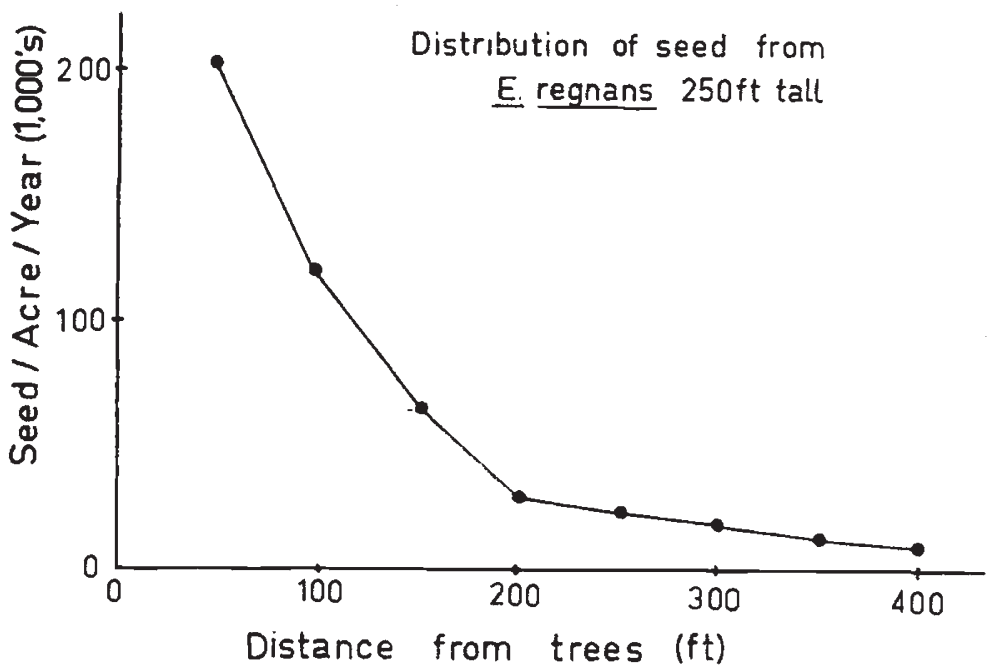

FrG. 2.-Distribution of seed of $E$. regnan; from forest-edge. Data from Gilbert ( $\left.195^{8}\right)$.

the ecotone takes place is scarcely affected by aspect, geology or drainage. The formation of lakes of cold air in the frost hollows of the button-grass plains may be important. Costin (1954) has pointed 
out similar patterns in the Snowy Mountains where, on slopes rising from the snow-grass plains, $E$. rubida occurs both above and below $E$. dalrympleana, the lower transition being about as sharp as the pauciflora-gigantea transition in Tasmania, the upper one more gradual as we might expect. Next to nothing is known about the physiological or ecological reasons for these interspecific selection systems between closely related species. Are the diagnostic characters themselves of any selective value?

\section{INTRASPECIFIC SELECTION}

We cannot hope to answer such questions easily unless we can compare the differing characteristics one at a time, so to speak. In other words to understand community-ecology, we must seek and find relevant gene-ecology where the populations or plants or gametes differ in one or a few selectively important genes. My first example deals with clinal variation in waxy glaucousness. About eight out of the twenty-four Tasmanian species of eucalypt show this variation. In the more exposed habitats - alpine savannah woodland as compared with mixed eucalypt/rainforest or on the dry upland plains compared with the valleys-the trees develop leaves and twigs covered with thick, light-scattering, water-repellent layers of wax-crystals. In the less exposed environments the leaves are still wax-covered but the wax is chemically different and deposited as films or broader crystals which are not light-scattering and much less water-repellent. The difference, as seen under the electron microscope, is illustrated in Hall et al. (1965) and in coccifera, gigantea, gunnii and urnigera it has proved to be genetic.

Where the ecological gradient is steep, the genes controlling wax are distributed in a correspondingly steep cline. Phenotype clines going up the mountains from the north coastal plain in Tasmania are given in Barber (1955, I956). Some idea of the magnitude of the selective forces can be obtained by comparing the frequencies of glaucous trees in the mature forest with the frequencies in their openpollinated seedlings. Barber and Jackson (1957) have shown for urnigera on Mt. Wellington, S. Tasmania, that the cline in seedlings is less steep than that in the more mature forest which has been naturally selected. If the cline is in equilibrium, glaucous seedlings must be weeded out at low elevations, whilst at high elevations green seedlings must be selected against. It is fairly clear that selective coefficients must be high-measured in per cent., not 0.1 per cent.at either end of the cline. The coefficients must also change sign somewhere up the mountain. A proper analysis demands a knowledge of the mean free path of a gene per generation (Haldane, I948).

\section{THE MEAN FREE PATH OF A GENE}

In these intraspecific clines, the mean free path of a gene is compounded of $(a)$ that of seeds, and $(b)$ that of pollen grains. We have 
seen that the mean free path of a seed is probably about one-half of the height of the tree. The mean free path of a pollen grain is more difficult to estimate. We require more natural history. As its name implies, urnigera has urn-shaped fruits owing to the development of a sunken nectary round the base of the style on top of the inferior ovary. Urnigera flowers secrete copious pools of nectar which can overflow the urn. The species flowers in mid-winter over a period of two or three months. Insects are very few and sluggish at this time of year. The flowering trees in winter are visited by possums (Trichosurus) which chew the sugary tops off the flowers. They probably spread pollen attached to their fur. Clearly the mean free path of possum-borne pollen will be a few yards. More important pollinators are birds-honey-eaters (Melithreptus and Meliornis) and parrots (Lathamus). On sunny days, flocks of ten or twenty birds fly from tree to tree. They probably fly up the mountain as the sun gains in strength and down again as the shadows lengthen. They must be efficient randomisers of the genes in the pollen grains.

This diversity of pollinators will almost certainly make the distribution of pollen pronouncedly leptokurtic. Crane and Mather (1943), Bateman (1950) and Wright (1952) have shown that even when pollination is by a single agent, e.g. bees in radishes, or wind in maize or pine trees, the distribution of pollen is leptokurtic. In urnigera the full distribution is made up of components each of different standard deviation and probably of differing kurtosis. Fig. 3 gives a theoretical diagram assuming 10 per cent. insect pollination with standard deviation of 5 yards, ro per cent. possum pollination with standard deviation of 25 yards and 80 per cent. bird pollination with standard deviation of 100 yards. These figures are mere guesses to illustrate possibilities. They underestimate the leptokurtosis because $f$ have assumed that each agent distributes pollen grains normally. On this must be superimposed the distribution of genes in seeds again with a leptokurtic distribution with a standard deviation of, say, 25 to $5^{\circ}$ yards, depending on the height of the seed-tree.

The estimation of the mean free path of a gene is a complex matter. In addition to the information guessed at above, we need to know whether the populations are made up of self-sterile or self-fertile or partially self-fertile individuals. There is no information for urnigera. In related eucalypt species Pryor (195I and unpubl.) has shown that some individuals may be self-sterile either wholly or partially. The flowers are also markedly protandrous. What effects do these factors have on the mean free path? Again what effects does plant density have on mean free path? There is a wide field of work here for anyone with a bent for natural history and experimental ingenuity in labelling pollen grains or seed with radio-tracers.

Unless we continually bear these aspects of natural history in mind, we will continually underestimate the power and efficacy of natural selection. Wherever a gene is distributed clinally or in a 
mosaic (which is really a series of steep and interlocking clines) we should always attempt to compare the interquartile distance, $I$, along the cline with the mean free path of the gene, $\lambda$. If they are both likely to be of the same order of magnitude, strong selection varying from place to place will be necessary to preserve the pattern of variation. A good example of a situation where $I$ and $\lambda$ are of the same order of

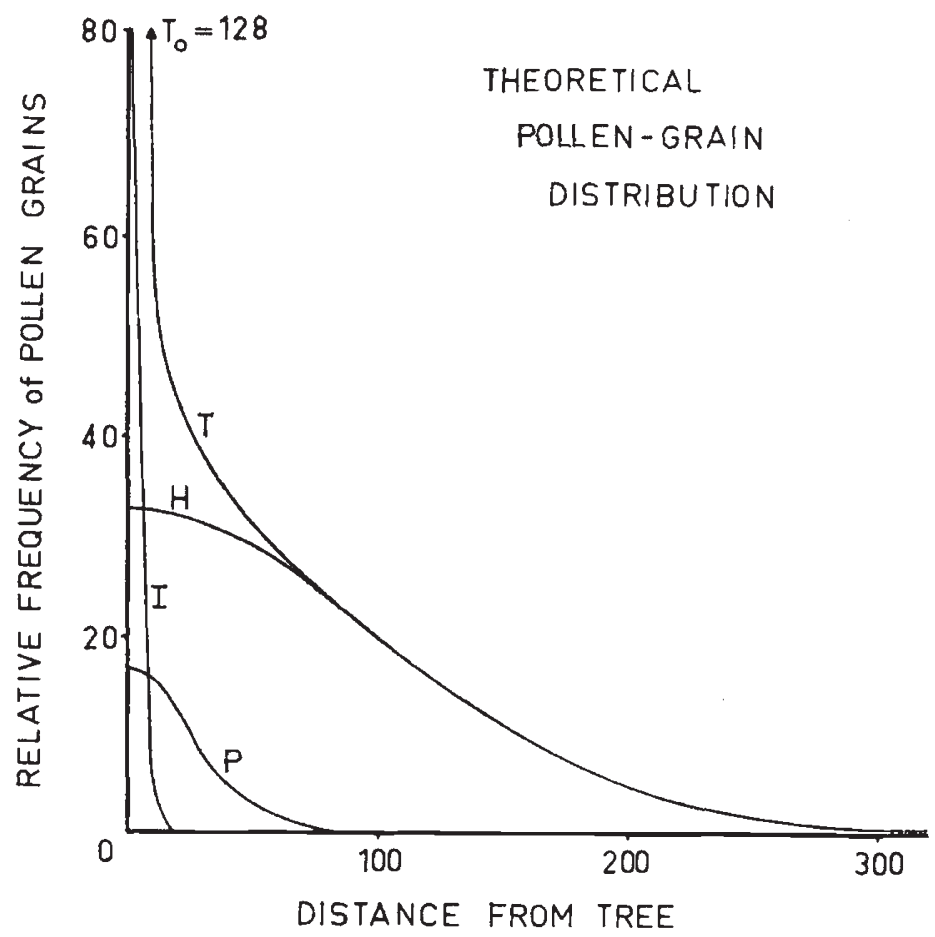

Frg. 3.-Theoretical distribution of pollen grains where diversity of pollinators exists. Total distribution, $T$, is supposed to be made up of 10 per cent. insect-borne pollen, $I$, Io per cent. possum-borne pollen, $P$, and 80 per cent. carried by honey-eaters, $H$.

magnitude is probably to be found in Bradshaw's (1952) work on the genotypic adaptation of species of Agrostis to mine-tailings rich in heavy metals. If the ecological factor were not so clearly definable, we might be tempted to analyse such patterns of variation in terms of "drift" unless we tried to estimate $I$ and $\lambda$. Epling et al. (1960) give data on flower colour variation in Linanthus parrya, a desert annual, which show $I$ to be $50-100 \mathrm{ft}$. The plant is pollinated by beetles and has dust-like seeds which may remain dormant for several years. $\lambda$ is thus probably of the same order as $I$. Selection, not drift (cf. Wright, 1943), must control the gene-distribution.

Possibly another consequence of the leptokurtic distribution of genes is the general uniformity of a species population. In a search for clines and polymorphisms we may tend to forget that even if we have isolated ten or a hundred such genes, the vast majority of loci will show no variability beyond the small amount dictated by the 
balance between unfavourable mutation and selection. Clines and polymorphisms are exceptional situations. In true polymorphisms the heterozygote is the most successful; in stable clines the two homozygotes are the most successful in two different and contrasting environments. There is no need to think that loci with such variation are more important in evolution. At the other loci, we must postulate that favourable mutations are continually arising on an evolutionary time-scale or that, as the environment changes, "old " mutations become advantageous. These mutations can spread rapidly through the population using, so to speak, the long tail of the leptokurtic distribution. Even if such genes are neutral from the point of view of selection in part of the species range, they will, if selected strongly enough in another part of the range, replace the old allele, and genetic uniformity is again attained (Fisher, 1937).

\section{CLINAL ANALYSIS OF VARIATION}

The barks provide good diagnostic characters between eucalypt species, although more variation exists than is often believed. The bark may vary from the " gum ", where it is smooth and shed annually, to a variety of rough-barks where the bark is persistent and either coarsely fibrous, as in "stringybarks", finely fibrous as in "boxes", scaley as in "bloodwoods" or hard and deeply fissured as in the " ironbarks". In addition there are the "half-barks" which have rough persistent bark on the main trunk and smooth branches with deciduous bark-a fascinating and seemingly pointless system of variation between related and unrelated species. Certainly the variation pattern has originated several times during evolution in different subgenera and sections of the genus. The taxonomist with his passion for "typification" and the giving and arguing about names, has not really clarified the variation pattern. There has been a tendency to define "species" solely on differences in bark, e.g. Johnston's ( I 962) recent definition of corticosa which is simply rough-barked aromaphloia. and pryoriana which is roughbarked viminalis, or Blakely's coolibah var. arida, which is smoothbarked microtheca. When one finds " halfbarks " and " quarter-barks" in these populations, clearly some genetic analysis is called for.

Coolibah and microtheca show a beautiful clinal pattern in the Northern Territory between the heavy, black clay soils of the Barkly Tableland and the sandy, red, spinifex soils. Almost the same analysis is possible using pryoriana and viminalis between the sandhills on the shores of Westernport Bay and the hills of the hinterland of Victoria.

On the clay soils of the Barkly, microtheca is restricted to the creek banks which are, of course, dry in winter. The trees are full roughbarks. The Lorne River rises in the Barkly and almost loses itself in the spinifex. The oddest things happen to the coolibahs as the river approaches the spinifex. First they tend to leave the creek side and march out into the spinifex. They do not usually get far and are 
probably restricted to the better watered stretches with some subterranean water. In the spinifex, the trees are dwarf, smooth-barked gums. Using an arbitrary score for bark-o for wholly smooth to Ioo wholly rough - the clinal variation shown in fig. 4 is obtained. The interquartile distance is about I-2 miles. This is greater than in urnigera on Mount Wellington where it is less than 400 yards. However, it is again of the same order as the mean free path of the genes controlling the phenotypic difference. Possibly $\lambda$ is longer for the coolibah than for urnigera. The seeds are shed in August and presumably do not germinate until the "wet" which starts in late November or early

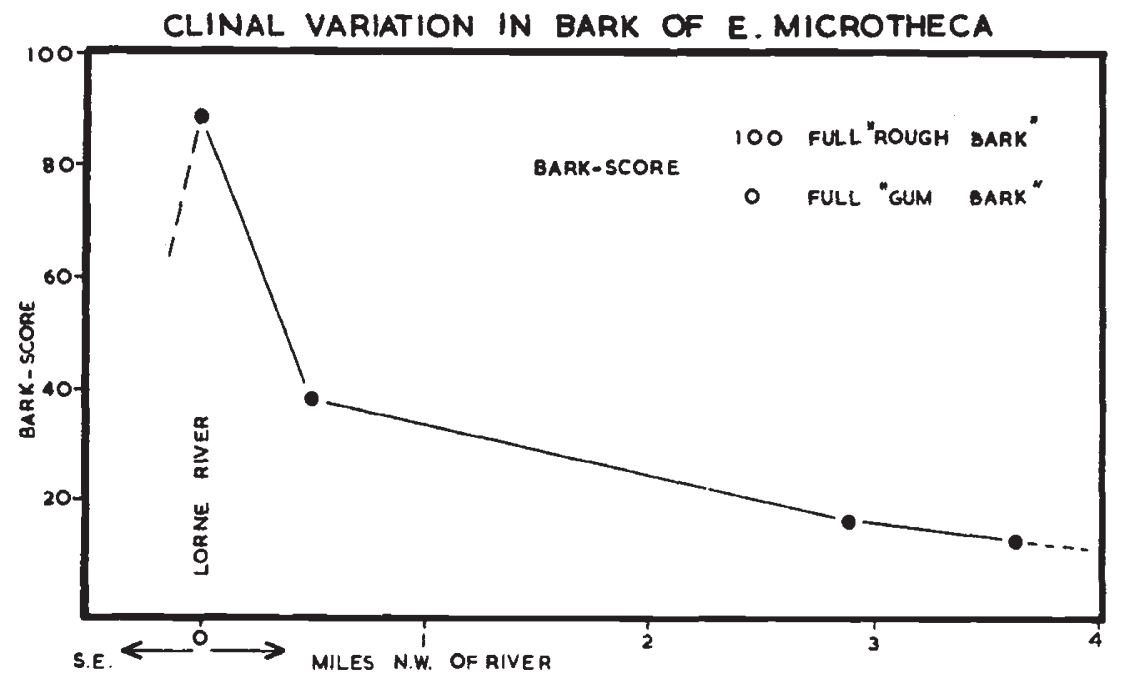

Fig. 4.-Clinal variation in type of bark of Eucalyptus microtheca; Lorne River, Barkly Tableland, Northern Territory of Australia. Each point represents mean bark score of roo-200 trees.

Score o-completely smooth decorticating bark (" gum ");

25-less than half trunk with persistent, rough bark; remainder smooth;

5o-trunk rough; branches smooth;

75 -trunk and primary branches rough, secondary branches smooth; soo-wholly rough.

December. The seeds clearly can be well randomised by wind and flood. So, again, we must postulate large selective coefficients to preserve the cline.

No progeny tests on this cline have been done, but it would be surprising if the bark differences are not genetic. In the cline, trees of very different bark-grading may grow within a few feet of one another. Any environmental modification seems to be excluded and bark differences have been found to segregate in open pollinated progenies of another species, E. gunnii from Tasmania. Pryor et al. (1956) show strong heritability of bark characteristics in the $F_{2}$ of the interspecific hybrids between $E$. rossii $\times$ robertsoni and $E$. eleophora $\times$ maculosa.

Our work on clinal variation in glaucousness in the urn-fruited gum on Mount Wellington involved raising 80 progenies of about 5o seedlings each. Eighteen of these progenies were planted out 
to test for other clinal variation correlated with height and also for polymorphic variation. Two of the experiments involved 6 progenies planted as a Latin square with blocks of four seedlings, i.e. 24 seedlings/progeny. In these experiments we have tried to estimate whether significant differences exist between progenies originating from different altitudes on the mountain. In addition to waxy glaucousness the cline on the mountain shows variation in a number of characteristics which include tree-height, leaf-shape,

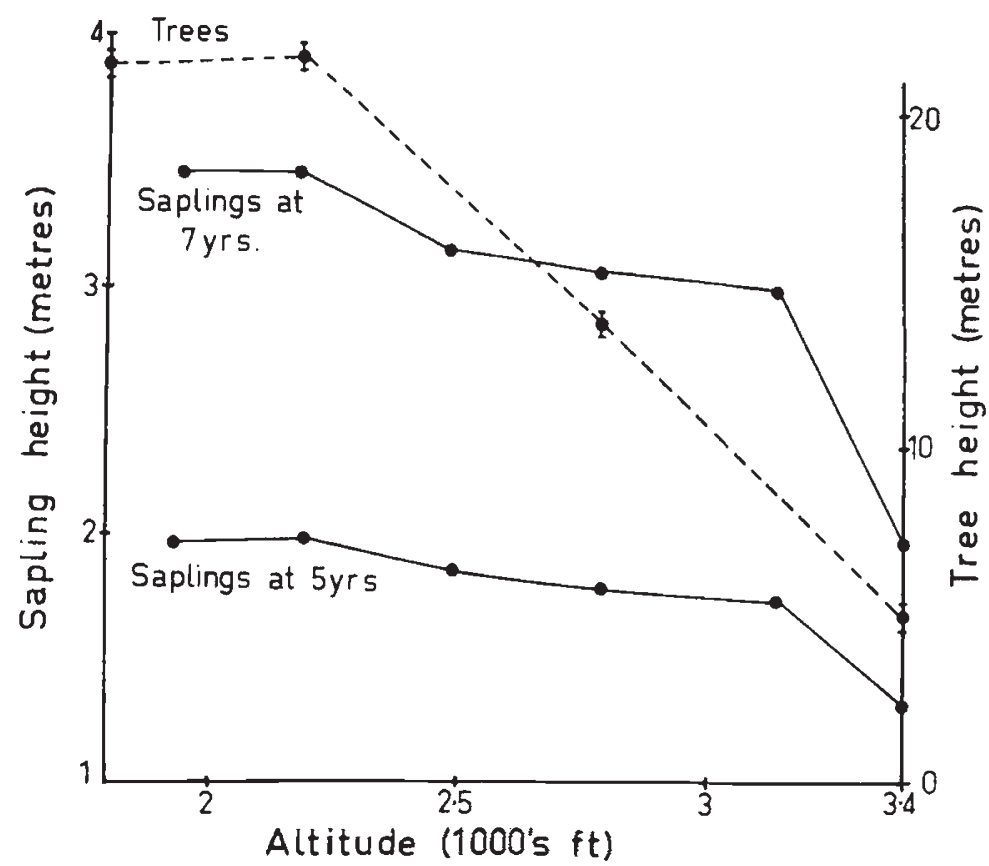

FrG. 5.-Ordinates of dotted curve gives cline in tree height of Eucalyptus urnigera plotted against altitude at which trees were growing on Mt. Wellington, Tasmania. Ordinates of full curves give mean heights at 5 and 7 years old of saplings of 6 open-pollinated progenies grown in a Latin square at Collinsvale, Tasmania; abscissa is altitude on the Mountain of the mother from which seed was collected. Difference in progeny means is statistically significant at $\mathbf{P}<0 \cdot 0$.

persistence of juvenile foliage, anthocyanin content of young expanding leaves, etc. In the experiments carried out in the relatively uniform environment of the experimental plantation, all these characteristics together with time to first flowering, show significant interprogeny variation. The variation patterns are of two types. Tree-height (growth-rate), leaf-shape, persistence of juvenile foliage are clinal with altitude and thus show the same pattern of variation as waxy glaucousness (fig. 5). A different pattern is shown by anthocyanin content. Fig. 6 shows that it can only properly be described as polymorphic. For time to first flowering, the data are not yet sufficient to decide whether variation is clinal or polymorphic-probably the former. 
It is, perhaps, significant that work on another species, $E$. dalrympleana, has shown that anthocyanin content is polymorphic over most of its distributional area in Tasmania. There are some indications of a cyclic system of selection with green forms lacking anthocyanin becoming more successful as the forest matures (Barber unpubl.). Whether such a system is working in urnigera is unknown. However, it may be significant that the apparent peak in anthocyanin content at about $2700 \mathrm{ft}$. coincides with a known fire track up the mountain (Gilbert unpubl.). Here the forest has been kept young and open, thus possibly favouring the red forms.

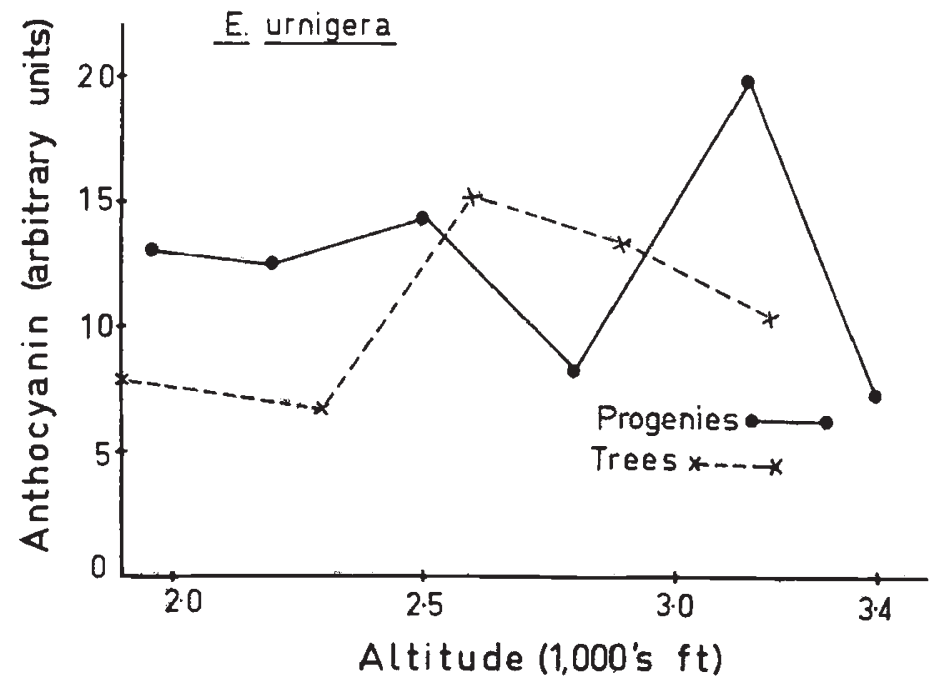

Fig. 6.-Anthocyanin content of young expanding leaves of E. urnigera. Dotted curve is mean of five samples each of 25 trees growing on Mt. Wellington; full curve represents mean content from 6 progenies grown in Latin square (see legend to fig. 5). Difference in progeny means is significant at $\mathrm{P}<0 \cdot 01$.

\section{THE EVOLUTION OF A CLINE}

The existence of a number of clinally varying phenotypes all correlated with the one ecological variable, namely altitude on the mountain, raises a number of important problems.

First, are the clines the result of pleiotropic gene action? If they are, this would, perhaps, simplify the genetics but not the ecology. There is no evidence that pleiotropy is a major cause of the correlation. There appears to be no obvious physiological link-up of the various characters and the progenies often show undoubted genetic recombinations. We will assume that separate acts of selection have created each of the clines.

Second, is there any evidence that chains of selection exist? By this I mean, can we say that selection at the $B$ locus has been dependent on prior selection at the $A$ locus? Again, there is no evidence for such a chain among the major phenotypic differences. Within the 
graded phenotypes of any one characteristic a selection chain may exist. For example, Harland showed many years ago that glaucousness in Ricinus depends on a basic gene with intensifiers and pattern genes which were apparently without phenotypic effect in the absence of the basic gene. It is possible that such a situation exists in urnigera, in which case selection for the basic gene will have anticipated selection for the modifiers. I am assuming that the different forms of wax deposited on the leaves are of direct importance for survival in the different environments, not some undiscovered pleiotropic effect of the genes concerned. Barber and Thomas (unpubl.) have shown that the water-repellency and light-reflection of the glaucous phenotypes have a number of important effects on frost-resistance, transpiration in mist, insect and fungus attack, leaf temperature and water relations, etc. The major problem is not finding important physiological effects caused by the difference in waxiness; but deciding which is the relevant effect in the particular ecological situation of this cline.

Third, what effects will these correlated selection processes have on the evolution of the cline? Let me try to illustrate this problem by a hypothetical example. Let us suppose a mutation, $A_{2}$, arises at a locus previously occupied by gene $A_{1}$. The mutation enables the population to extend its range along an ecological gradient. In the old environment the mutation has been selected against; in the new it is the favoured allele. Let us call this change in selective coefficient $\Delta s_{A}$. Now let a further mutation, $B_{2}$, arise at a different locus which, again, is successful in the new environment. Phenotypically and genetically, this second mutation is assumed to be independent of the first. From the point of view of selection the second mutation may be partly or wholly dependent on the first act of selection depending on whether its advantage is restricted to the new ecological range produced by the first selection or whether it is also advantageous in part of the old territory. If the two clines at the two loci overlap, the alleles will become correlated. Both are dependent on the same ecological variable, $h$. If $q_{A}$ is the frequency of allele $A_{2}$ and $q_{B}$ is the frequency of $B_{2}$,

$$
q_{A}=f_{1}(h) \text { and } q_{B}=f_{2}(h) .
$$

In a sense these equations can be considered to be parametric equations in $h$ for the two gene-frequencies. From the point of view of selection they will lead to a correlation, $\rho$, of $A_{2}$ and $B_{2}$ in the same pollen-grain. Thus an $A_{2}$ gene migrating along the cline has a chance $\rho$ of being associated with $B_{2}$. If the change in selective coefficient which gave rise to the cline at the $B$ locus is $\Delta s_{B}$, the coefficient of selection operating with respect to $A_{2}$ will apparently be enhanced.

$$
\Delta s_{A T}=\Delta s_{A}+\rho \Delta s_{B} .
$$

Thus, correlated selection will tend to steepen the cline. We can expect the steepening to be most intense round any break or irregularity 
in the ecological gradient or where the gradient happens to be steepest. We can also imagine the steepening to be most intense round a genetic cline involving a gene, the selection of which was crucial in the occupation of new territory.

These deductions are of some interest with regard to the possibility of sympatric speciation and of the significance of so-called "introgressive hybridisation". In both cases it sometimes appears to be more an article of faith than of science to deny the possibility of the first and uncritically accept the second.

The conditions for stability in multi-genic clines do not seem to have received the attention they deserve. Fisher (I930 and 1958) is almost alone in attempting to consider them. He points out that, with the steepening of the cline, if the mean free path of genes remains the same an increasing number of individuals will find themselves in an unsuitable environment, the unsuitability being dictated by an increasing number of selectively correlated genes. The increasing wastage so caused can be reduced only by reducing the mean free path of genes in zygote and gamete. In plants, particularly the eucalypts we have been considering, the mean free path will often be more a function of pollen rather than of zygote. Thus, a selective pressure may arise favouring a diminution either of the mean free path of genes in the pollen or in the effectiveness of pollen transported long distances. There are several mechanisms by which these decreases can be brought about gradually. There may be a selection for increased self-fertilisation. We do not know enough about the mating system of eucalypts to be sure that such mechanisms have arisen in the genus. The reason for the extraordinary changes in mating system discussed by Darwin (1890) in the orchids (cf. Stebbins and Ferlan, 1956) may be connected with the need to reduce the mean free path of the pollen grain possibly caused by the arrival of a wide-ranging and relatively catholic pollinator. Such a process will be attended by all the dangers of inbreeding, some of which may be minimised by strong selection for heterozygotes. This process, however, simply transfers the reproductive wastage from one point in the life-cycle to another.

A more efficient mechanism will be the gradual origin of barriers to crossing. In plants, this can come about by a gradual change in flowering time, the change buttressing and increasing any ecologically controlled difference already present along the cline. It is, perhaps, significant that pairs of closely related eucalypt species often flower at different times, e.g. urnigera (June-Aug.) and gunnii (Jan.-Feb.), obliqua (Jan.-Feb.) and regnans (March-April), rubida (Jan.-Feb.) and viminalis (Feb.-March), etc. Such isolation mechanisms will not be very stable, particularly if the species are transplanted out of their natural habitats, where conditions of growth (and selection) are radically changed. The breakdown of delicately adjusted barriers to crossing may help to explain the difficulties taxonomists have in identifying species of large genera like Eucalyptus, Rhododendron, etc., 
after transplantation overseas. However, sufficient has been said to show that, contrary to some authorities (e.g. Dobzhansky, I95I, and Mayr, 1948 and 1963 ), the possibility of sympatric speciation, by which I mean speciation occurring within a distance, say, of five to fifty times the mean free path of a gene per generation, cannot be dismissed lightly. We return to this problem later.

\section{THE COST OF SELECTION AND DENSITY-DEPENDENT DEATH RATES}

It has been apparent since Fisher's (1930) analysis of the problem that one of the advantages conferred by the process of speciation is the prevention of the break-up of adapted gene complexes by unrestricted hybridisation and the consequent segregation of unbalanced recombinants. Unrestricted recombination leads to reproductive wastage which is avoided by speciation. All selective processes involve a wastage or cost. The cost of selection has been considered on an evolutionary scale by Haldane (I957 and I96I) and by Kimura (I96I). These two authors show that the cost of replacing one allele by another is independent of $s$, the coefficient of selection, when the process is considered as a simple replacement on an evolutionary time-scale and $s$ is small. In a particular generation, this can scarcely be true and, in a cline or in a polymorphism, no net change in gene frequency may occur despite a high cost of selection. This continuous cost reaches its maximum in forms like Oenothera lamarckiana where all homozygotes are killed by the genes they contain. The cost of selection is 50 per cent. per generation. Are there any escapes from this high cost? O. muricata or Leucopogon juniperinus (Smith-White, 1948) or the Canine roses (Erlanson, I93I) show one method. It is a method based on gametic selection and thus in a sense the cost is transferred from the population of zygotes to the population of gametes. However, where the segregation process is rigorously controlled as in Leucopogon, the unwanted gametes are not formed at all, the two complementary types being produced by the special mechanism of the chromosomes, one on the male side and the other on the female side. The origin of such specialised cytological mechanisms is one measure of the extremities some populations have been forced into by natural selection to avoid the cost of that selection. Here the overriding advantage seems to have been the "pursuit of hybridity", to use Darlington's phraseology (1939).

Whilst the advantages of heterozygosity have been demonstrated times without number (cf. Lerner, I 954), evolutionary progress depends largely on the replacement of one allele by another. We saw earlier that such replacement, because of high selective coefficients, may often have a high cost. Are there other mechanisms which can reduce the cost? Haldane (1957), in a vivid example, has pointed out that it is difficult to imagine the moth, Biston betularia, surviving at all, if the 
re-adaptation necessitated by the sudden change in its environment about 150 generations ago had required selection at a number of loci as intense as at the locus of the gene for industrial melanism. Kettlewell ( I956) has shown that the old non-melanic form, adapted to conditions before the Industrial Revolution, when released in the blackened countryside of central England, can suffer death rates of 50 per cent. per day by predatory birds. Here selection is directly reducing the number of parents available to produce the next generation and, moreover, reducing it right at the end of the life-cycle.

What will be the cost of selection if selection operates at other times in the life-cycle? Here I am using cost in a way different from that used by Haldane. I shall define the cost of selection in a particular generation as the reduction brought about by selection in the number of parents available to produce the succeeding generation. We automatically tend to think that if selection removes, say, Io per cent. of individuals, all carrying a deleterious gene, the selection will automatically reduce the numbers of parents by the same amount. This is true if selection operates, as it does in the moths, on the parents immediately before they produce the next generation. If selection occurs earlier in the life-history it will be true only if what we may call the accidental or non-selective death rate is independent of the density of the population. If, on the other hand, the non-selective death rate is density-dependent, as it undoubtedly is in overcrowded seedlings of forest trees, it is possible for selection to occur early in the life-history and have no effect on the number of parents surviving to produce the next generation. In other words, part or the whole of the cost of selection can be debited against non-selective deaths which must occur whether or not genetic selection takes place during the same period.

Let us look at two hypothetical situations in detail and then see how far they may fit Nature. The problem of density-dependent factors limiting population numbers has given rise to violent controversy among zoological ecologists. As Moran (1962) points out, the controversy among the zoologists is primarily a matter of definition. It is convenient to define the terminology mathematically.

At time, $t_{0}$, let the population number per unit area or volume be $N_{0}$. We shall normally be interested in individuals at a certain stage of development, e.g. seedlings of a forest tree when we can ignore (except as part of the environment) the adult trees.

If the death rate $\frac{d \mathrm{~N}}{d t}$ is directly proportional to the number of survivors at any time $t$

$$
\text { i.e. } \frac{d \mathrm{~N}}{d t}=k\left(\mathrm{~N}_{0}-\mathrm{N}\right)
$$

we define the death rate of this population as density-independent. The model is, of course, the familiar law of radioactive decay where 
the chance of the death of an atom of radium does not depend on its neighbours. this:

If, however, the death rate increases with density we can express.

$$
\frac{d \mathrm{~N}}{d t}=k\left(\mathrm{~N}_{0}-\mathrm{N}\right)^{n}
$$

where $n$ is some exponent greater than I.

Let us take $n=2$.

Integration of these equations gives for the number of survivors at time $t$

and

$$
\left(\mathrm{N}_{0}-\mathrm{N}\right)=\mathrm{N}_{0} e^{-k t} \text { for equation (I) }
$$

$$
\left(\mathrm{N}_{0}-\mathrm{N}\right)=\frac{\mathrm{N}_{0}}{\mathrm{I}+k \mathrm{~N}_{0} t} \text { for equation (2). }
$$

Before we try and see what effect these different models may have on the cost of selection we ought to discuss their applicability to natural populations. Much of available data, e.g. agricultural experiments on density of sowing and seed yield, cannot be used since yield per unit area not per plant is given. All we can conclude is that competition limits yield to a ceiling both by reducing yield per plant and the number of plants surviving to contribute to that yield. Professor C. M. Donald (1963) of the Waite Agricultural Institute has recently surveyed some of these problems and from data personally communicated to me, the number of plants in densely sown wheat or pasture species (grasses and clovers) does not follow (I) and may follow (2), but the data are not sufficient to evaluate $n$ accurately except to say it appears to be greater than I after dense sowings have grown sufficiently.

As an example of another type of data, Gilbert (1958) gives the curve illustrated in fig. 7 for decrease in numbers of Eucalyptus regnans with age. This species regenerates only when the rainforest understorey is destroyed by fire so that even-aged stands occur. Reciprocal plotting gives a straight line so that here $n=2$ and the death rate is density-dependent. In actual fact, the numbers of regnans per acre may fall from more than 200,000 at year I after a "wild-fire" to Io to the acre 400 years later when the trees are senile.

We may expect to find examples of density-independence where plants are widely scattered so that they have no true neighbours of their own species competing with them, e.g. young plantations of forest-trees or the scattered migrants into a new area which is being colonised.

Let us assume that selection removes a proportion $s$ of populations characterised by equation (I) and (2) at time $t_{0}$. Fig. 8 shows the consequences where, to take an extreme example, 50 per cent. are supposed removed. If, after selection, the population number obeys 


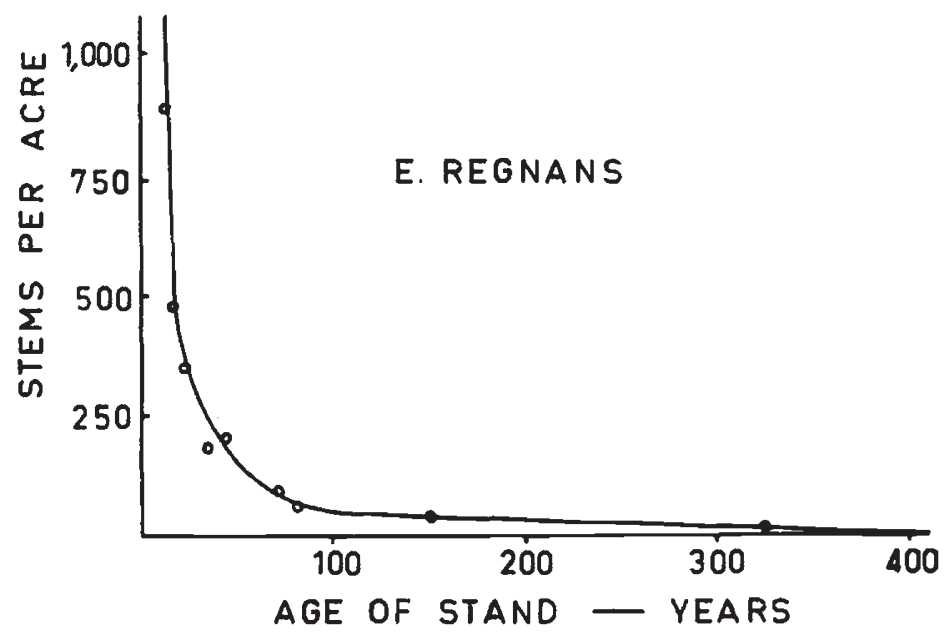

Fic. 7.-Numbers of trees per acre plotted against age for Eucalyptus regnans in S. Tasmania. Curve redrawn from Gilbert (1958). Regeneration of regnans occurs only after forestfire. The stands are thus predominantly even-aged.

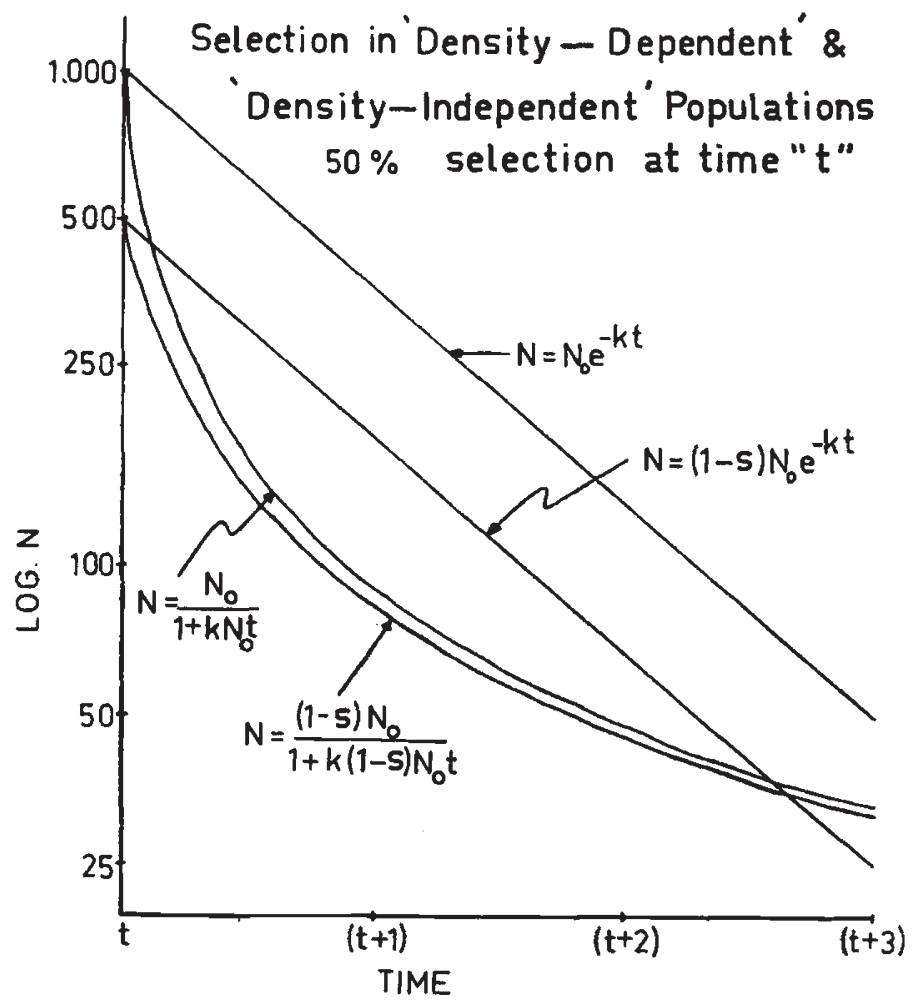

Fro. 8.-Logarithmic plots of models of populations with density-dependent and densityindependent death rates. In both cases $5^{\circ}$ per cent. of populations are assumed to be removed by genetic selection at time $t$. For further explanation see text. 
equation (I) until reproduction, the number of parents surviving to reproduce the next generation at time $t$ is reduced proportionately. If, on the other hand, the population number obeys equation (2), we can see that the number tends asymptotically towards the number in an unselected population.

For the two cases we can represent the number of survivors after the act of selection:

$$
(\mathrm{I}-s) \mathrm{N}_{0}-\mathrm{N}=(\mathrm{I}-s) \mathrm{N}_{0} e^{-k t}
$$

i.e. ratio of survivors with selection to survivors without selection, $\mathrm{R}=(\mathrm{I}-s)$ for all values of $t$.

$$
(\mathrm{I}-s) \mathbf{N}_{\mathbf{0}}-\mathrm{N}=\frac{(\mathrm{I}-s) \mathbf{N}_{\mathbf{0}}}{\mathrm{I}+k(\mathrm{I}-s) \mathbf{N}_{\mathbf{0}} t}
$$

so that

$$
\mathrm{R}=\frac{(\mathrm{I}-s)\left(\mathrm{I}+k \mathrm{~N}_{0} t\right)}{\mathrm{I}+k(\mathrm{I}-s) \mathrm{N}_{0} t}
$$

which tends to $\mathrm{I}$, as $t$ tends to $\infty$.

In the graphs of fig. 8, I have illustrated the case where $s=0.5$ and the population number falls by a factor of 30 in the unselected population. $\mathrm{R}$ here is equal to 0.96 , i.e. most of the cost of this extreme selection has been debited against non-selective deaths, which must occur because of overcrowding. Even where the population number decreases by a factor of $10, R=0.91$ instead of 0.5 as in the first model population.

Perhaps a simple example will show that this elementary mathematical analysis is, so to speak, also intuitively true. Let us take an annual clover like Trifolium subterraneum which has so successfully colonised southern Australia. The dormant seed population builds up amazingly so that a warm autumn rain will turn the countryside from brown to green owing to millions of cotyledons sprouting almost overnight. Many chlorophyll deficient lethals are known, which die at the one or two leaf stage. We can easily see that with a high density of seed, the death of these chlorotic seedlings will have no effect on numbers of parents 6 months later. So many green seedlings must die if the plants are to grow at all. If, on the other hand, the seeds were widely spaced, the deaths caused by the lethal genes could result in the same proportionate reduction in the number of parents a few months later.

\section{DENSITY-DEPENDENCE AND EVOLUTIONARY PROGRESS}

Several consequences of these models are worth discussing. The first concerns the probability of speciation in a multi-genic cline. A phase during the ecological development of a population in which density-dependent death rates occur, has the effect of greatly reducing the cost of any genetic selective processes occurring before that phase. Density-dependence should thus hinder the development by natural 
selection of the barriers to crossing which result in speciation. This may be one of the reasons for the partial failure of speciation in so many genera of forest-trees, e.g. Quercus, Populus, Salix, Eucalyptus, Cupressus and Pinus. Competition (or "interference ": Harper, 1961) among herbs may have different consequences from the point of view of selection. Competition here has apparently led to a great plasticity in growth form, overcrowded stands compensating by reducing the size of plants at maturity. Such plasticity is precluded among the dominants of the high forest. Another possibility is that barriers to crossing may usually arise when a colonising species is rare and selective deaths cannot be compensated by density-dependence. In other words, speciation may be less likely in populations of the ecological dominants than in their rare associated species.

A second possibility concerns the well-known phenomenon of evolutionary convergence. In the Angiosperms it is so widespread that certain authors, e.g. Good (1956), are constrained to see in it a denial of the efficacy of selection. The Australian flora is full of the most spectacular examples. The "ericoid" habit is developed in the Epacrids, the Labiates, Proteaceæ, Myrtaceæ, Leguminosæ, etc. We even have an "ericoid" grass and an "ericoid" lily. There is no difficulty in classifying these plants if they are in flower. An evolutionary change affecting floral characteristics is likely to have a higher cost than one affecting vegetative characteristics. Is this one reason for the conservatism of reproductive characteristics?

A third consequence is, perhaps, the easy origin of what the zoologist. terms "larval " and the botanist "juvenile" characteristics. These all affect the young offspring. Has it been possible to interpolate them in the life-history so frequently because the cost of selection for them is negligible owing to density-dependent death rates? Botanists have been loathe to discuss the origin of such characteristics. I suppose the usual explanation offered under pressure might still be an Haeckelian inertia. This is clearly not sufficient. Many closely related species of eucalypt, e.g. viminalis and rubida, seeana and tereticornis, radiata and salicifolia, etc., may be so similar as adults as to be virtually unidentifiable as herbarium specimens but unmistakable as seedlings or coppice. The evidence of comparative morphology points to a divergent evolution of juvenile characteristics rather than a convergence of adult characteristics.

There is one last speculation which I should like to import into botany from zoology. De Beer (1951) and Hardy (1954) have suggested that major evolutionary changes in animals have often come about by larval forms becoming sexually mature in the phenomenon known as neoteny or pædomorphosis. Has the same phenomenon occurred in plants? The genus Eucalyptus has many instances of species flowering in the opposite-leaf stage characteristic of juvenile foliage of other species. Examples are cordata in the Globulares, risdoni in the peppermints, vernicosa in the Semi-unicolores. Are these neotenic forms? I 
believe this is the simplest expanation for their origin, and an acceleration in time of flowering relative to other morphological development is clearly a characteristic which can be selected at a very low cost.

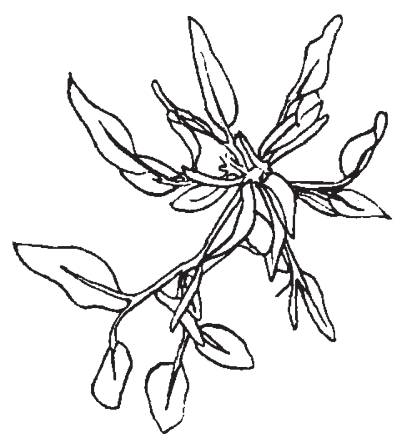

C V

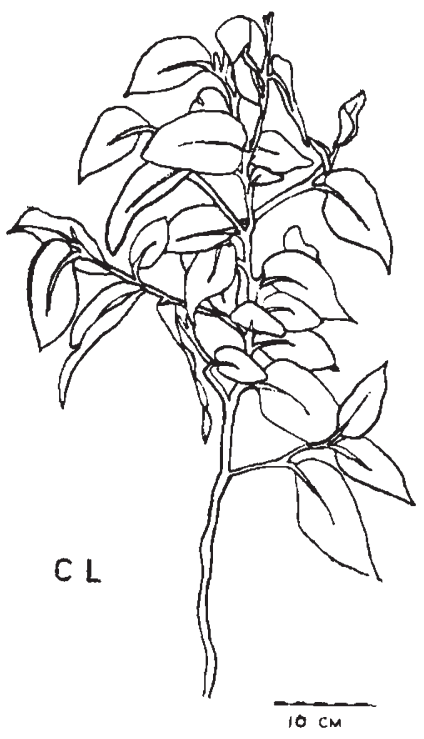

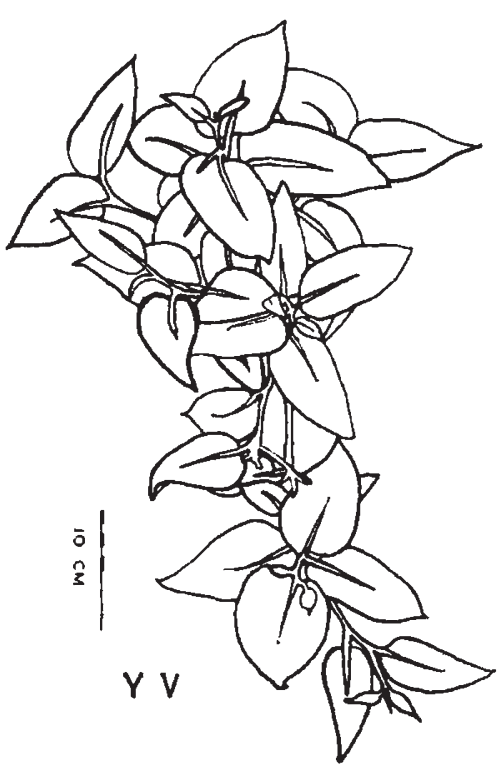

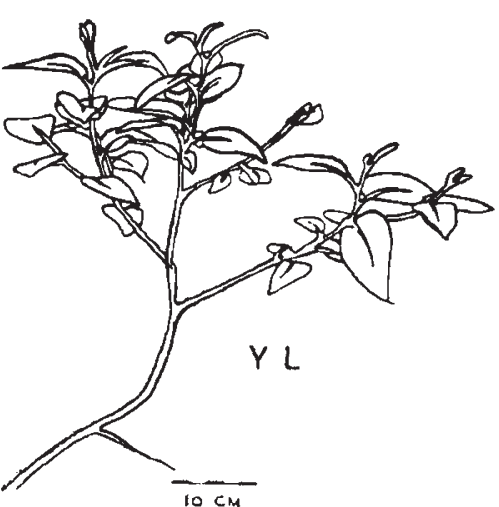

Fic. 9.-Leaf-orientation in seedlings of Eucalyplus obliqua from Tasmania and northern New South Wales. Drawings made from photographs of seedlings from vertically above, V, and from the side, L. C-seedling from Collinsavale, S. Tasmania; Y-seedling from Yarrowitch, N. New South Wales.

The characteristics in which "plant-larvæ" differ from the adult are an odd collection-shape, orientation, arrangement, colour and anatomy of the leaves. Until recently it has seemed impossible that 
all such character differences could be adaptive. And yet, if evolu- vilary progress consists of the origin of adaptations by natural selection, it should be possible to show that these apparently trivial differences are important for survival at some stage of growth. Recent work by the physiologists, particularly those interested in the control of yield, is showing that, say, leaf orientation can be of crucial importance in growth. Watson and Witts (1959) have given cogent evidence that one of the major characters unconsciously selected for by generations of plant breeders to produce commercial sugar beet from wild Beta maritima may have been leaf-orientation and spacing. Donald (1962) has suggested a similar process in the cultural evolution of the wheats. These two workers look on the changes in leaf orientation and spacing as controlling the efficiency of light absorption for photosynthesis by the whole plant. They clearly will also have an effect on water-relations. A leaf illuminated by full sunlight, normally incident, is receiving far more light than it can use photosynthetically. All that the extra energy absorbed does, is to raise the leaf's temperatures thus increasing evaporation. Need we look further in order to design experiments to test the adaptiveness of the last clinally varying characteristic I will discuss? Fig. 9 shows seedlings of $E$. obliqua. Those with vertically orientated leaves are from Tasmania; the seedlings with horizontal leaves come from northern New South Wales. We are just starting experiments to determine which type survives better in the shade of competing weed-species so prevalent in the wet sclerophyll forests of the north and which type survives better in the open drier forests of the south.

I believe all the juvenile differences will be shown to be adaptive in certain environments. By using genetics to design experimental populations, the adaptive significances will be capable of definition experimentally. As mentioned above, Barber and Thomas (unpubl.) have shown that the water-repellent and light-reflecting wax-crystals on the surface of the leaf have a number of important physiological consequences.

\section{REPRODUCTIVE AND NON-REPRODUCTIVE ATOMS}

One way of summarising nineteenth-century science could be in terms of atomics and energetics. Atoms, philosophically, are of two types-the Daltonian non-reproductive atom and the Mendelian reproductive atom. Natural selection is a simple consequence of the existence of the Mendel atom, and perhaps it should now be referred to as the Mendel-Darwin-Muller atom. As such its study demands the attention not only of our "molecular" colleagues who are tending, perhaps, to usurp it as their own; but particularly of ecologists and physiologists who in their writings seem so often to ignore the consequences of Natural Selection in populations of selfreproductive and mutating atoms of heredity. One reason for this 
ignorance is that the genetics of higher organisms is still time-consum ing. However, the design of experimental populations segregating for all sorts of possibly adaptive character differences is now a simple matter. Their study physiologically should enable us to obtain the ecological answer to many of the classical problems of adaptive chemistry, physiology and morphology.

\section{SUMMARY}

A number of cases of natural selection in producing clinal variation in populations of Australian plants are described and partially analysed on a genetic basis. Full genetic analysis involves more knowledge than we possess of the mean free path of a gene per generation. However, sufficient is known to enable the demonstration of very high selective coefficients at the two ends of clines which may vary in length from yards to miles. The selective coefficients must change sign at some point along the length of the clines.

The problems of the further evolution of clines are discussed. Analysis in one case has shown that genes affecting at least five different characteristics are all clinally distributed along the same ecological gradient. The existence of such ecologically correlated genetical variation means that the cline for any one characteristic must have steepened during the evolution of the cline as a whole. It is suggested that, where reproductive loss remains high, such steepening can result in sympatric speciation. However, the cost of selective removal of genes transported to the unfavourable environment may be extremely small if the selection takes place early in the growth of a population in which the death rate is density-dependent, e.g. overcrowded saplings of forest trees. Under these conditions clines may be stable for long periods giving rise to the taxonomic problems so characteristic of genera of ecological dominants, e.g. Eucalyptus, Quercus, Cupressus, etc.

A brief discussion is given of the evolutionary consequences of this low-cost but high-intensity selection. It may have been partially responsible (I) for the interpolation of "juvenile" or "larval" characters into the life-history of both plants and animals, with (2) the possiblity of neotenic evolutionary transformations; and (3) for examples of convergence of vegetative characteristics whilst the reproductive characters remain conservative.

A deduction from this view is that it should be possible to demonstrate a selective advantage for such juvenile characteristics, as differences in shape, orientation and arrangement, texture and surface covering of leaves. A beginning has been mide on the analysis of clinal variation from this physiological and ecological view-point.

Acknoweledgnents.-I wish to thank Mr Michael Barber for help in making the transect illustrated in fig. I and Miss Geraldine Kelly for fig. 9. Drs R. K. Crowden and W. D. Jackson helped in many ways including analysis of variation in the urnigera plantation and in critical discussion. 
Throughout the paper the nomenclature of Eucalyptus is as in Blakely (1955) where " authorities" for the names used can be found. The recent spate of namechanges and transmigrations of names from one "species" to another have nothing to do with science except to make it more difficult to consult with and learn from past work of earlier generations of botanists and naturalists. It is becoming increasingly important that such work remain as intelligible as possible.

\section{REFERENCES}

BARBER, H. N. 1955. Adaptive gene-substitutions in Eucalyptus. Evolution, 9, I-14. BARBER, H. N. 1956. The natural history of natural selection. Austral. 7. Sci., $18,148-159$.

BARBER, H. N., AND JACKSON, W. D. 1957. Natural selection in action in Eucalyptus. Nature, 17.9, $1267-1269$.

Bateman, A. J. I950. Is gene dispersion normal? Heredity, 4, 353-363.

BRAdShaW, A. D. I952. Populations of Agrostis tenuis resistant to lead and zinc poisoning. Nature, 169 , 1098.

costin, A. B. 1954. The Ecosystems of the Monaro Region of New South Wales. Government Printer, Sydney.

CRANE, M. B., AND MATHER, K. 1943. Natural cross-pollination of crop plants. Ann. Appl. Biol., 30, 300-308.

DARLington, C.D. 1939. Evolution of Genetic Systems. C.U.P.

DARWIn, C. 1890 . The Fertilisation of Orchids. John Murray, London.

DE BEER, G. R. 1940. Embryos and Ancestors. Oxford U.P.

Dobzhansky, T. 195I. Genetics and the Origin of Species. Columbia U.P.

DONAld, C. M. 1962. In search of yield. 7. Aust. Inst. of Agric. Sci., 28, 17 I-1 78.

Donald, c. M. 1963. Competition among crop and pasture plants. Adv. in Agron., $15, \mathrm{I}-\mathrm{I} 18$.

EPLiNG, C., LEWIS, H., AND BALL, F. M. 1960 . The breeding group and seed storage. Evolution, 14, 238-255.

ERLANSON, E. W. I93r. Chromsome organization in Rosa. Cytologia, 2, 256-282.

FISHER, R. A. 1930, 1958. The Genetical Theory of Natural Selection. Oxford U.P., Ist and Dover, 2nd Ed.

Fisher, R. A. 1937. The wave of advance of advantageous genes. Ann. Eugenics, 7, 355-369.

GILbERT, J. M. 1958. Forest succession in the Florentine Valley, Tasmania. Proc. Roy. Soc. Tas., 93, 129-15 I.

GOOD, R. 1956. Features of Evolution in the Flowering Plants. Longmans, Green, London.

haldane, J. B. S. 1948. The theory of a cline. 7. Genet., $48,277$.

HALDANE, J. B. S. 1957. The cost of natural selection. 7. Genet., 55, 51 I-524.

haldane, J. B. s. $196 \mathrm{I}$. More precise expressions for the cost of selection. $\mathcal{J}$. Genet., 57,35 I-360.

hall, D. M., MATUS, A. I., LAMBERTon, J. A., AND BARBeR, H. N. 1965. Infra-specific variation in wax on leaf surfaces. Aust. 7. Biol. Sci., 18, 323-32.

HARDY, A. C. 1954. Escape from specialisation, in Evolution as a Process, p. 122, ed. Huxley, J. et al. Allen \& Unwin, London.

HARPER, J. L. I $96 \mathrm{r}$. Approaches to the study of plant competition in Mechanisms of Biological Competition. S.E.B. Symposium, 15, I-39.

Johnson, L. A. S. 1962. Studies in the taxonomy of Eucalyptus. Contrib. N.S.W. Herb., 3, 103-126.

KETTLEWELL, H. B. D. 1956. Further selection experiments on industrial melanism in the Lepidoptera. Heredity, 10, 287-303.

KIMURA, M. 1961. Natural selection as the process of accumulating genetic information in adaptive evolution. Genet. Res., 2, 127 -140.

i.erner, I. M. I 954. Genetic Homeostasis. Oliver and Boyd, Edinburgh. 
MAYR, E. 1947. Ecological factors in speciation. Evolution, $r, 263-288$.

MAYR, E. 1963. Animal Species and Evolution. Harvard U.P., Cambridge, Mass. MORAN, P. A. P. 1962. The Statistical Processes of Evolutionary Theory. Oxford U.P. PRYOR, L. D. I95I. Controlled pollination of Eucalyptus. Proc. Linn. Soc., N.S.W. PRYOR, L. D., CHATTAWAY, M. M., AND KLOOT, N. H. 1956. Inheritance of wood and bark characters in Eucalyptus. Aust. F. Bot., 4, 21 6-239.

smith-WHItE, s. 1955. The life history and genetic system of Leucopogon juniperinus. Heredity, 9, 79-91.

STEBbins, G. L., AND FERLAN, L. I956. Population variability, hybridization and introgression in some species of Ophrys. Evolution, 10, 32-46.

WATSON, D. Jn, AND WITTS, K. J. 1959. Net assimilation rates of wild and cultivated beets. Ann. Bot., 23, 431-439.

WRIGHT, J. W. I952. Pollen dispersion of some forest trees. Station Paper 46, N.E. Exp. Sta., U.S.D.A.

WRIGHT, s. 1943. An analysis of local variability of flower colour in Linanthus parrye. Genetics, 28, 139-1 56 . 